\title{
Nutrition labelling of pre-packaged foods in Belgrade, Serbia: current situation
}

\author{
Dragana B Davidović ${ }^{1, *}$, Dragan V Tomić ${ }^{2}$, Katarina Ž Paunović ${ }^{1}$, Nadja D Vasiljević ${ }^{1}$ and \\ Jagoda B Jorga ${ }^{1}$ \\ 'Institute for Hygiene and Medical Ecology, Faculty of Medicine, University of Belgrade, Dr Subotića 8, 11000 \\ Belgrade, Serbia: ${ }^{2}$ Clinic for Gastroenterology and Hepatology, Clinical Centre of Serbia, Faculty of Medicine, \\ University of Belgrade, Belgrade, Serbia
}

Submitted 8 April 2014: Final revision received 15 September 2014: Accepted 18 September 2014: First published online 6 November 2014

\begin{abstract}
Objective: To determine the presence of nutrition labels on pre-packaged food products, as well as to analyse the types of presentation.

Design: This was a descriptive study. The following characteristics were analysed: (i) presence and placement of the nutrition declaration (either as front-of-pack (FOP) or back-of-pack (BOP)); (ii) content of the presented information; (iii) presence of nutrition and health claims; and (iv) legibility of the written information.

Settings: Three different types of retailers in Belgrade, Serbia.

Subjects: A total of 2138 pre-packaged food products from ten categories.

Results: A nutrition declaration was found on $65.9 \%$ of all tested products. It was displayed on the back of the packaging of $62.7 \%$ of products and on the front of the packaging of $19.1 \%$ of products. BOP was the most commonly observed in breakfast cereals, soft drinks, milk and instant soups (in total over $90 \%$ ), and the least common in meat products $(21.5 \%)$. FOP was predominantly displayed on breakfast cereals $(65.0 \%)$ and the least frequently on milk products $(2 \cdot 4 \%)$. The 'Big 4' (energy value, protein, carbohydrate and fat contents) and the 'Big 4 with additional information' figured on $40.9 \%$ of products. The 'Big 8' ('Big 4' plus sugar, saturated fat, fibre and sodium contents) and the 'Big 8 with additional information' were present less frequently (20.5\%). Nutrition claims and health claims appeared on very few products $(6.6 \%$ and $6.3 \%$, respectively). The proportion of products with insufficient legibility was $31.5 \%$.

Conclusions: Nutrition labelling in Belgrade, Serbia is not satisfactory. Mandatory regulations may be the best way to improve the current situation.
\end{abstract}

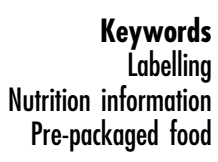

Labelling Pre-packaged food
The worldwide prevalence of overweight and obesity has been increasing at a dramatic rate over the last decades. According to the WHO, in 2008, 35\% of adults over the age of 20 years were overweight, whereas $10 \%$ of men and $14 \%$ of women worldwide were obese $\left(\mathrm{BMI} \geq 30 \mathrm{~kg} / \mathrm{m}^{2}\right)^{(1)}$. Overweight and obesity lead to adverse metabolic effects on blood pressure, cholesterol, TAG and insulin resistance. Risks of $\mathrm{CHD}$, ischaemic stroke, type 2 diabetes mellitus and some types of cancer increase steadily with increasing $\mathrm{BMI}^{(1-6)}$.

Many researchers recognize that the growing epidemic of chronic diseases in both developed and developing countries may be related to dietary and lifestyle changes ${ }^{(7-9)}$. The WHO emphasizes the role of diet and some dietary components in preventing and controlling morbidity and premature mortality resulting from non-communicable diseases ${ }^{(7)}$.
Similar to other developing countries, Serbia is currently undergoing a nutrition transition. Malnutrition and infectious diseases used to be the main cause of poor health in the early 20th century; however, chronic, noncommunicable diseases stand out the most today. Obesity has become highly prevalent and a severe public health issue in Serbia. The results of the Health Survey in Serbia from 2006 showed that $55.7 \%$ of the population was overweight, of whom $19.0 \%$ were obese, and $46.5 \%$ of adults suffered from arterial hypertension ${ }^{(10)}$. In 2011, $8.2 \%$ of the population in Serbia already suffered from diabetes $^{(11)}$. According to the International Diabetes Federation, the largest increase in the number of people with diabetes is expected in developing countries ${ }^{(11)}$. It is therefore expected that this growing trend will spread to Serbia as well. 
The range of foods available on the market is increasing around the world. At the same time, the proportion of people suffering from hypersensitivity reactions to food is increasing. The prevalence of reported hypersensitivity reactions to food ranges from $3 \%$ to $35 \%{ }^{(12)}$. It was even observed that $20 \%$ of people will change their diet due to the suspicion that they do not tolerate a certain food or its ingredients $^{(13)}$.

Having in mind the growing prevalence of diet-related diseases mentioned above, as one of the most important preventive measures, governments, retailers and food companies are promoting nutrition labelling in order to help consumers make adequate food choices ${ }^{(14)}$. The WHO included nutrition labelling as part of its global strategy on diet, physical activity and health. In order to help consumers make the adequate choice in accordance with health recommendations, legislation should provide accurate, standardized and comprehensive nutrition information on all foods ${ }^{(15)}$. Nutrition labels facilitate choices and access to nutrient-dense foods and are a very important part of a supportive environment ${ }^{(16)}$. Observational studies have consistently found a positive correlation between reading nutrition labels and healthier diets. Many consumers claim that nutrition labels influence their selection of foods ${ }^{(17-21)}$.

The format, content and position of nutrition labels have an important impact on consumers' perception and hence on their choice of product ${ }^{(22)}$. Existing studies indicate that some types of nutrition labels are more effective than others in helping consumers choose healthier products. For example, user-friendly labels that provide information at a glance (such as on the front of the package) influence consumers' buying behaviours and dietary intakes more effectively $^{(23,24)}$.

A nutrition label is a very powerful marketing tool as well. Marketing-based statements can lead consumers to a decision based on scientifically non-justifiable and tendentious statements. Because of that, and due to the broad use of nutrition labels in shops, fast-food restaurants, restaurants and cantinas, it is necessary to continuously improve both national and international legislation in the field $^{(17,22)}$. At present, declaration of nutrition information is voluntary in Serbia ${ }^{(25)}$ as well as in the European Union $(\mathrm{EU})^{(26)}$, unless a food product contains nutrition and/or health claims. Nutrition declaration will become mandatory in the EU in December 2016 ${ }^{(26)}$, whereas in Serbia this date has not yet been specified. In Serbia, the use of nutrition claims is regulated under the Regulation on Nutrition Labelling for Foodstuffs ${ }^{(27)}$, while the use of health claims is not currently defined by legislation. On the other hand, nutrition and health claims on food products are well regulated in the $\mathrm{EU}^{(28)}$.

The objective of the present research study was to determine the presence of nutrition labels on pre-packaged food products in retail stores in Belgrade, Serbia among different food categories, as well as to analyse the types of presentation.

\section{Methods}

The study was conducted in Belgrade, Serbia from March 2012 until June 2012. A survey of pre-packaged food products was carried out in three different food retail chains: 'Maxi Delhaize' (the largest food retail chain in the region), 'DIS Market' (the largest national food retail chain) and 'SOS Market' (discount/economy stores). The listed food retail chains were selected to allow for extensive coverage of different food manufacturers in order to present a complete availability of packaged food products in the territory of Serbia. The selected retailers also cover different customer profiles. As the lead international food retail chain in the region, 'Maxi Delhaize' stores mainly attract consumers with higher incomes. 'DIS Market', the greatest national retail chain in Central Serbia, advertises itself as offering the best value for money and mainly attracts middle-class customers. 'SOS Market' retail chain is designed for people with low incomes. For the purpose of the present research study, the survey of products was performed in the largest stores of each retail chain.

To summarize the above, the selected stores not only offer a wide variety of popular brands and foods present in Serbia but also cover different consumer profiles.

Ten categories of pre-packaged products were included in the survey and these product categories were defined as follows.

1. Breakfast cereals: cereal products that are consumed for breakfast with milk, tea or yoghurt.

2. Bread and toast: products based on flour, containing the word 'bread'/'toast' on the packaging.

3. Milk: products containing the word 'milk' on the packaging; refers to cow's, sheep's or goat's milk, natural or with added flavour.

4. Yoghurt: fermented milk product, containing the word 'yoghurt' on the packaging, natural or with added fruit.

5. Cheese: milk product, containing the word 'cheese' on the packaging.

6. Meat products: products of animal origin produced from muscle, fat, intestines and skin by different technological methods of processing and preservation.

7. Biscuits: products containing flour, sugar and fat, with or without a filling or a topping.

8. Ready meals: ready-packed meals containing protein sources (meat, fish or similar), carbohydrate sources (potatoes, pasta or similar) and vegetables, as well as the variety of products that do not contain all of the three elements.

9. Instant soups: powdered products which dissolve in water; containing the word 'soup' on the packaging.

10. Soft drinks: carbonated, non-carbonated and fruit drinks stored in bottles or cans, and used as refreshments.

According to the Serbian household budget survey ${ }^{(29)}$, these food groups are the most common parts of diets in 
Serbia. That was the primary reason for selecting them for survey. These products represent the packaged foods that can be consumed at different times and on different occasions, i.e. foods that are used daily as a meal or a snack, both at home and outdoors.

The survey included all pre-packaged products, within the ten listed categories, that were available on the shelves in each store at the time of the survey. In the first store we visited, the survey covered all of the available products in each category. In the next two stores we analysed only the products that were not found in the previous one, in order to avoid unintentional repetition of the products surveyed.

The following characteristics of the product packaging were analysed.

1. The presence of a nutrition declaration, defined as information on the energy value and the content of certain nutrients in the food ${ }^{(30)}$.

2. The position of the nutrition declaration: either as front-of-pack (FOP) or back-of-pack (BOP). FOP information is defined as information that is located on the front of the box, in the central field of vision with the name of the product. The remaining area of the package is defined as $\mathrm{BOP}^{(31)}$.

3. The type of presentation of nutrition information: linear, table, FOP scheme-signpost, traffic light system or health logo. The 'FOP scheme-signpost' is supplementary nutrition information which represents the repetition of the elements of comprehensive declarations that are essential for health. The 'traffic light system' gives a warning about the level of certain nutrients in the product by using colours. The 'health logo' is supplementary nutrition information in the form of a symbol (which may vary from one logo to another) on the package. Its use is restricted to food products that fulfil certain nutrition criteria. A product marked with a 'health logo' can be considered a healthier choice in that particular category.

4. The content of the information presented on the BOP, defined as the 'Big 4', the 'Big 8', the 'Big 4 with additional information' or the 'Big 8 with additional information' as follows:

a. the 'Big 4' refers to energy value and the amounts of protein, carbohydrate and fat;

b. the 'Big 8' refers to the 'Big 4' plus the amounts of sugar, saturated fat, fibre and sodium;

c. the 'Big 4 with additional information' refers to the 'Big 4' plus other nutrients but less than the 'Big 8'; and

d. the 'Big 8 with additional information' refers to the 'Big 8' plus other nutrients ${ }^{(30)}$.

5. The information on the Guideline Daily Amounts (GDA) ${ }^{(32)}$

6. The font size and legibility of relevant written information. The font size was measured using a ruler. It was considered adequate if the $x$-height of the font size was equal to or greater than $1.2 \mathrm{~mm}$. In the case of packages whose largest surface area was less than $80 \mathrm{~cm}^{2}$, the $x$-height of the font size was considered adequate if it was equal to or greater than $0.9 \mathrm{~mm}^{(26)}$. Legibility is the degree to which individual characters in text are understandable and/or recognizable based on the appearance. It is determined by various elements, such as font size, letter spacing, spacing between lines, type of colour, typeface, width-toheight ratio of the letters, surface of the material and significant contrast between the print and the background. Legibility was evaluated subjectively.

7. The presence of nutrition claims. Nutrition claims indicate that a food has particular nutrition properties originating from its energy value and/or its content of certain nutrients ${ }^{(28)}$.

8. The format of the nutrition claims: text, numeric or symbol.

9. The type of nutrition claims:

a. 'nutrient content claim' refers to a nutrition claim that describes the level of a nutrient contained in a food or its energy value ${ }^{(33)}$; and

b. 'nutrient comparative claim' refers to a nutrition claim that compares the nutrient levels and/or energy value of two or more food products ${ }^{(33)}$.

10. The presence of health claims. A health claim is defined as the statement of a relationship between the food or its certain nutrients and health ${ }^{(28)}$.

11. The format of the health claim: text or symbol.

12. The type of health claim:

a. 'function claim' refers to a health claim that describes the physiological role of the nutrient in growth, development and functions of the body ${ }^{(33)}$;

b. 'general health claim' refers to a health claim concerning specific beneficial effects of the consumption of a food or its constituents. Such health claims relate to a positive contribution to health, its improvement or a function of preserving health ${ }^{(33)}$; and

c. 'reduction of disease risk claim' refers to a health claim relating the consumption of a food or food constituent to the reduced risk of developing a disease or health-related condition ${ }^{(33)}$.

The general management of all three retailers approved the survey and the collected information/data.

Descriptive statistics were used to analyse the results.

\section{Results}

The study included 2138 pre-packaged food products from ten categories as presented in Table 1. The results showed that $65.9 \%$ of all tested products contained some nutrition declaration. The presence of a nutrition declaration differed significantly by food category. The highest prevalence of nutrition information ( $90 \%$ or more) was 
observed in the following categories: breakfast cereals, soft drinks, milk and instant soups. Furthermore, $78.0 \%$ of biscuits and $71.7 \%$ of yoghurts contained some nutrition information. In contrast, nutrition information was rarely present in the bread and toast category, as well as in meat products, where about one-third of all products had nutrition labels. A nutrition declaration was observed on about half of all cheese examined (55.4\%) and on $42.0 \%$ of ready meals.

Analysis of the frequency of the presence of BOP and FOP nutrition information revealed that BOP information was displayed on $62.7 \%$ of pre-packaged food products, whereas FOP information was displayed on $19.1 \%$ of products. The FOP form was mainly used to highlight certain data about the products that were already listed in the BOP table. In a very few products (3.2\%) FOP information was the only nutrition information available. This was noted among meat products, cheese, yoghurt and biscuits.

Figure 1 shows a large difference in the frequency of presence of nutrition information on the front and back of

Table 1 Number of products and the frequency of nutrition information presence per audited category. Survey of 2138 pre-packaged food products in three different types of retailers in Belgrade, Serbia, March-June 2012

\begin{tabular}{lccc}
\hline & & \multicolumn{2}{c}{ Nutrition information } \\
\cline { 3 - 4 } Category & Number of products & $n$ & $\%$ \\
\hline Breakfast cereals & 100 & 92 & $92 \cdot 0$ \\
Bread and toast & 119 & 38 & 31.9 \\
Milk & 83 & 76 & $91 \cdot 6$ \\
Yoghurt & 223 & 160 & $71 \cdot 7$ \\
Cheese & 213 & 118 & $55 \cdot 4$ \\
Meat products & 452 & 132 & 29.2 \\
Biscuits & 314 & 245 & $78 \cdot 0$ \\
Ready meals & 69 & 29 & $42 \cdot 0$ \\
Instant soups & 127 & 116 & 91.3 \\
Soft drinks & 438 & 402 & 91.8 \\
Total & 2138 & 1408 & 65.9 \\
\hline
\end{tabular}

the packaging (FOP and BOP respectively) across the surveyed products in different categories. The BOP table was the dominant mode of display of nutrition information in all observed groups. It was most commonly observed in the following food categories: breakfast cereals, soft drinks, milk and instant soups (over $90 \%$ ), and the least common in meat products $(21.5 \%)$. For the FOP style of information, the leading category was breakfast cereals where it figured on $65.0 \%$ of products. On the other hand, in other product categories, the FOP information was less often recorded. In food categories such as biscuits, instant soups and soft drinks, FOP information was recorded on approximately a quarter of the examined products. In the other groups, however, the proportion of FOP information was only up to $10 \%$. Only a few milk products $(2.4 \%)$ contained the FOP information.

The most widespread type of BOP presentation of nutrition information was the nutrition table, which figured on $95 \%$ of all products with BOP information, whereas linear listing was displayed on $5 \%$ of all products containing BOP information.

As for the contents of the nutrition declaration, the 'Big 4 ' and the 'Big 4 with additional information' figured on $40.9 \%$ of all products. The 'Big 8' and the 'Big 8 with additional information' were present half as often (20.5\%). Energy content alone was recorded on $1.1 \%$ of all selected products. More specifically, information about the energy content alone was found on meat products $(0.8 \%)$, breakfast cereals $(0 \cdot 2 \%)$ and ready meals $(0 \cdot 1 \%)$.

Figure 2 displays the contents of the nutrition information on the BOP table by product category. It shows that breakfast cereals and biscuits contained the most extensive nutrition labels. A nutrition table in the form of the 'Big 8' or the 'Big 8 with additional information' was registered on $75.0 \%$ of breakfast cereals and $49.7 \%$ of biscuits.

In the bread and toast category half of the products had more extensive information. On the other hand, the 'Big 4' or the 'Big 4 with additional information' was present on

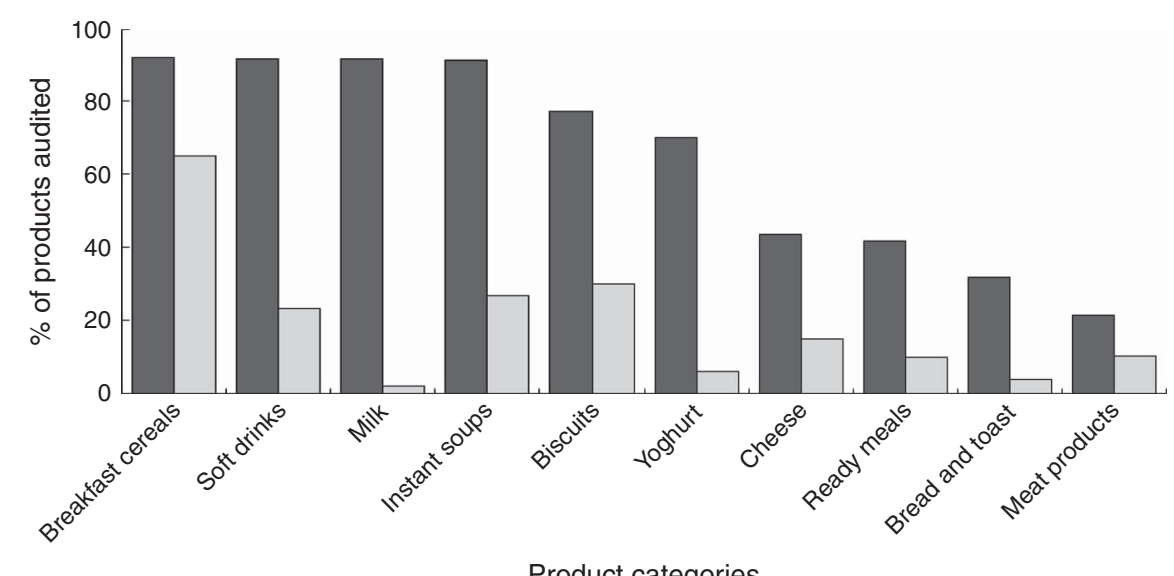

Product categories

Fig. 1 Frequency of the presence of nutrition information on the back of the packaging (BOP; $\square$ ) and on the front of the packaging (FOP; $\square$ ) for the ten product categories. Survey of 2138 pre-packaged food products in three different types of retailers in Belgrade, Serbia, March-June 2012 


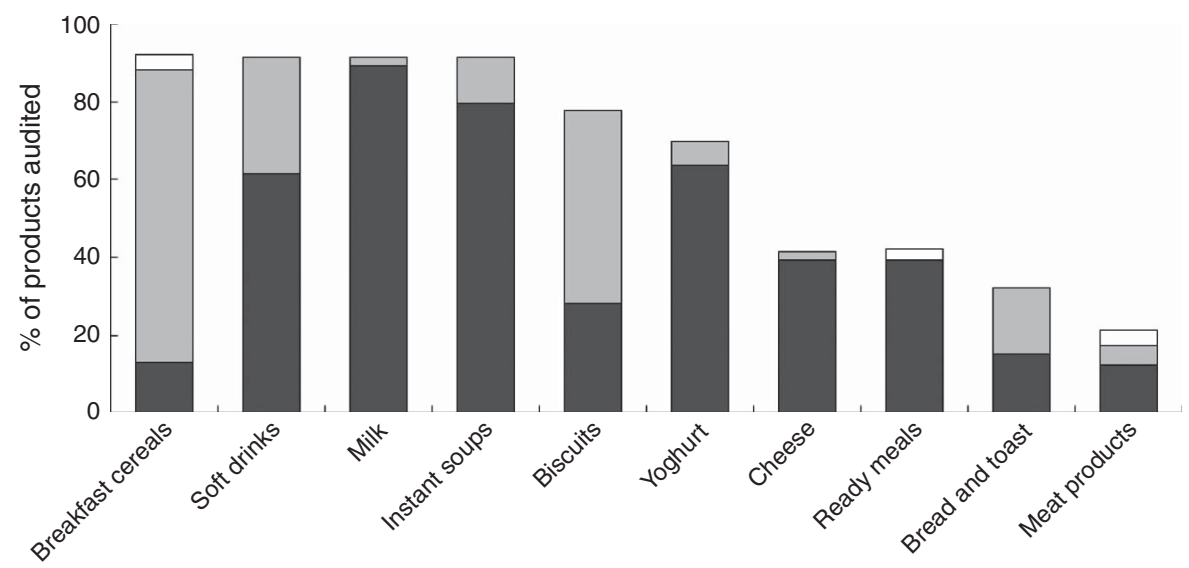

Product categories

Fig. 2 Contents of the nutrition information ( $\square$, 'Big 4' and 'Big 4 with additional information'; $\square$, 'Big 8' and 'Big 8 with additional information'; $\square$, energy value) on the back-of-pack (BOP) table for the ten product categories. Survey of 2138 pre-packaged food products in three different types of retailers in Belgrade, Serbia, March-June 2012

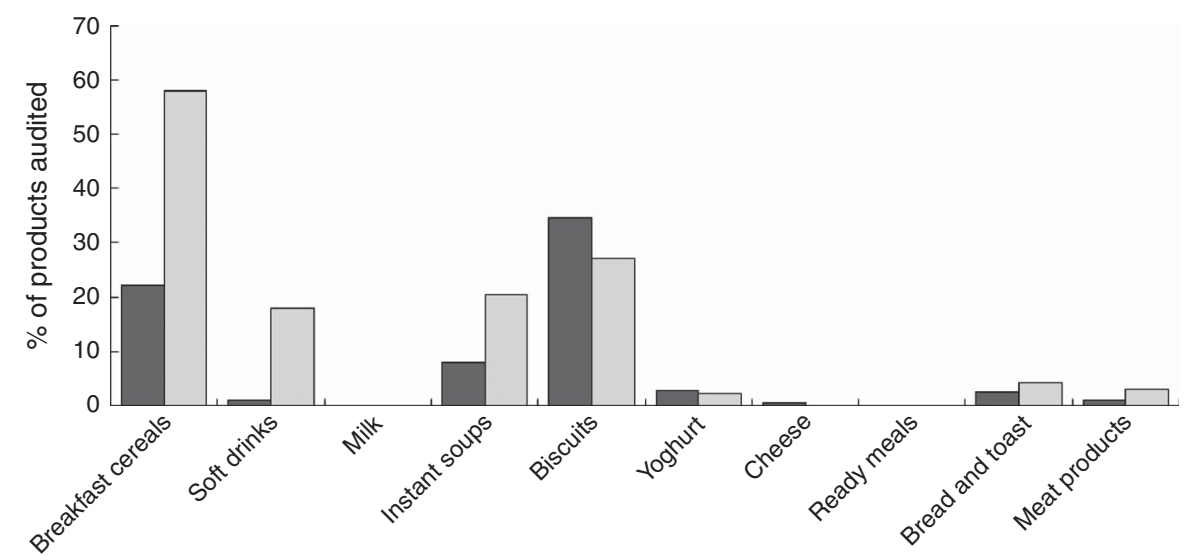

Product categories

Fig. 3 Frequency of the presence of Guideline Daily Amounts (GDA) information on the back of the packaging (BOP; $\square$, GDA on BOP) and on the front of the packaging (FOP; $\square$, GDA on FOP) for the ten product categories. Survey of 2138 pre-packaged food products in three different types of retailers in Belgrade, Serbia, March-June 2012

products from the following categories: milk (89.1\%), instant soups (79.5\%) and yoghurt (63.6\%). For milk and yoghurt products, the only additional information within the 'Big 4' was calcium content. The only category that contained the 'Big 4' or the 'Big 8' tables without additional information was instant soups. Among the investigated food categories where nutrition labels were less frequently present (cheese, ready meals and meat products), the 'Big 4' was the dominant way of labelling. The 'Big 4' figured on about $40 \%$ of cheese and ready meals and on about $12 \%$ of meat products.

Predominantly, the nutrition labels were expressed per $100 \mathrm{~g}$ of the product with the exception of $3.5 \%$ of the investigated products. The additional information per serving was specified on $23.0 \%$ of the products.

The GDA value was shown on $15.7 \%$ of the products. The GDA system was present in the BOP table $(7.4 \%$ of food products) and the FOP scheme (12.6\% of products).
Figure 3 presents the results of the analysis of the presence of the GDA information depending on food category. The GDA value was usually provided on breakfast cereals ( $60.0 \%$ of products) and biscuits ( $45.9 \%$ of products). In the category of breakfast cereals, the GDA was more often displayed within the FOP schemes (58\% of products) than on the BOP table ( $22 \%$ of products). Among instant soups and soft drinks the GDA value was provided on about $20 \%$ of the products. In the other groups, this information was presented on less than $5 \%$ of the products or was not present at all. The traffic light labelling style was not recorded on any of the reviewed products.

The font analysis included the $x$-height and legibility of the nutrition information. The font size was found to be too small for $27.6 \%$ of all products. Additionally, the proportion of products with insufficient legibility increased to $31.5 \%$ when the other factors contributing to unsatisfactory legibility were taken into account. 


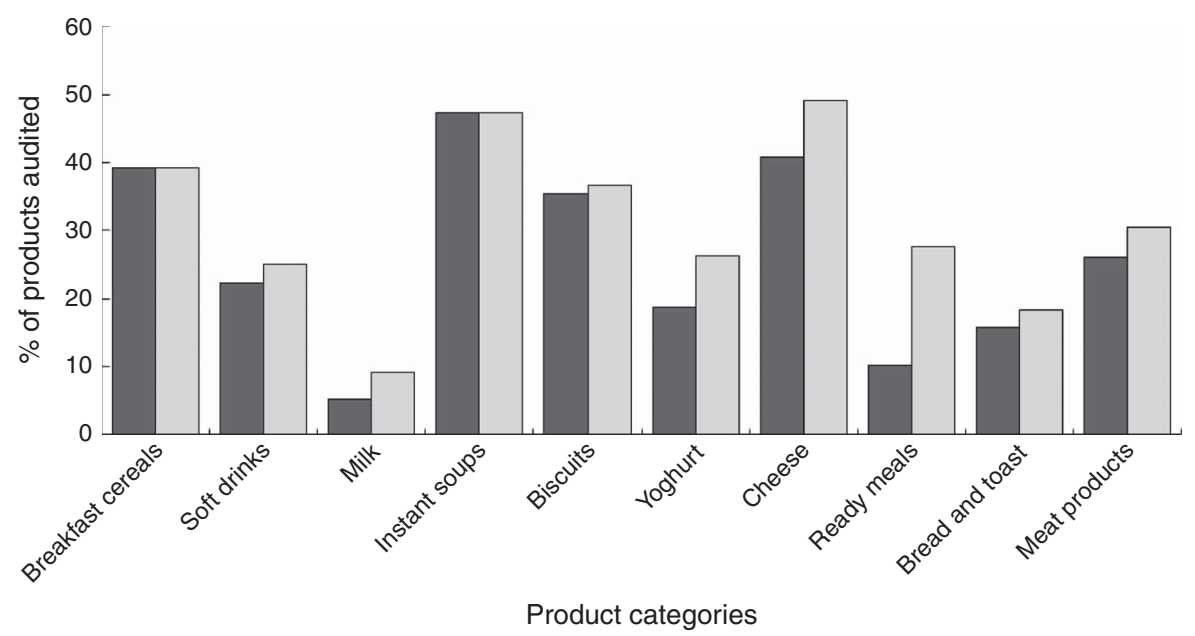

Fig. 4 Frequency of the presence of inadequate font $(\square$, inadequate $x$-height; $\square$, poor legibility) in the nutrition information for the ten product categories. Survey of 2138 pre-packaged food products in three different types of retailers in Belgrade, Serbia, March-June 2012

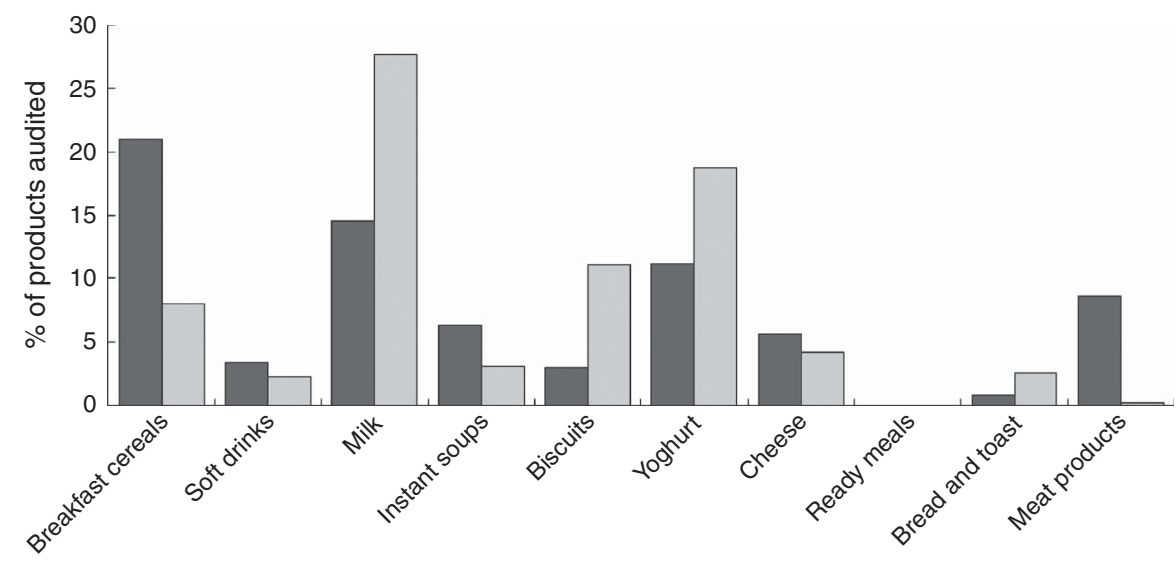

Product categories

Fig. 5 Frequency of the presence of nutrition claims $(\square)$ and health claims $(\square)$ in the nutrition information for the ten product categories. Survey of 2138 pre-packaged food products in three different types of retailers in Belgrade, Serbia, March-June 2012

Figure 4 shows the frequency of appearance of inadequate font by product category. Inadequate font size was recorded on a wide range of products, varying from approximately $5 \%$ to $50 \%$ of the products within individual food categories. Too small font size was observed on over $40 \%$ of products within the following categories: instant soups, cheese, breakfast cereals and biscuits. The most satisfactory category in relation to font size was milk, where only $5.3 \%$ of the products had $x$-height less than the required EU mandatory level. In some product categories, $x$-height was appropriate but there was a problem of poor legibility. This was particularly evident among the following categories: cheese (49.2\%), ready meals (27.6\%) and yoghurt (26.3\%).

The presence of health logos was very small $(3.7 \%)$. A health logo was registered on the following categories: breakfast cereals $(18.0 \%)$, yoghurt $(11.2 \%)$ and biscuits $(11.1 \%)$. Among other food categories, this information was not highlighted (data not shown).
The presence of nutrition and health claims is shown in Fig. 5. Nutrition claims were recorded on $6.6 \%$ of all products and health claims on $6.3 \%$ of all products.

The nutrition claims were usually present on nutrientdense, so-called 'healthy' food products: milk (14.5\%) and yoghurt (11.2\%). They also appeared on breakfast cereals $(21.0 \%)$, which are perceived as 'healthy' by the general public. In many cases, however, their nutrition content (high sugar level) does not truly meet evidencebased criteria for healthy food products. The nutrition claims are of the utmost importance in these three food categories that are commonly used in everyday diet. They can act as guidelines for consumers in choosing a product of a certain quality, e.g. with less fat or more fibre. In the other groups, nutrition claims were rarely observed (less than $10 \%$ of the surveyed products).

Analysing the format of the nutrition claims, text was the most commonly used format, displayed on $87 \cdot 3 \%$ of all 
products that had nutrition claims. The numerical format was present on the diary products: yoghurt and milk (about $65 \%$ ), but less frequently on cheese and soft drinks (about $25 \%$ ). In the other groups of products this format was not present. The symbol format was present only on two groups of products: on nearly a quarter of breakfast cereals and on all biscuits (the whole grain symbol). It was observed that a text statement with the same message simultaneously supported the symbol representation on the products.

Analysis of the type of nutrition claims revealed that the 'nutrient content claim' was present on the majority of products in all of the groups. 'Nutrient comparative claims' were noticed in a greater proportion on products such as yoghurt ( $60 \%$ of all yoghurts had nutrition claims) and soft drinks ( $40 \%$ of all soft drinks had nutrition claims).

Health claims, as well as nutrition claims, were present more often on the so-called 'healthy products'. They were present on $27.7 \%$ of milk products, on $18.8 \%$ of yoghurts and on $8 \%$ of breakfast cereals. Health claims were noticed on $11.1 \%$ of biscuits, which may not be considered a healthy food choice due to their high energy and low nutrition value. Among the other groups of products, health claims were sporadically present (less than $5 \%$ of the surveyed products).

The health claims were often in the form of text (97\%). However, in the three groups where health claims were most commonly present, the manufacturer decided to present them by a symbol (e.g. heart-shaped symbol, slim human figure). This form of presentation of the health claim was present on $55 \%$ of milk and yoghurt products and on all breakfast cereals.

The presented health claims were mainly addressing the physiological role of some nutrients in the growth, development and functioning of the body, so-called 'function claims' $(57 \cdot 1 \%)$, while 'general health claims' were less frequent $(25.9 \%)$. Finally, health claims related to the 'reduction of disease risk' were present on $17 \%$ of all the food products investigated.

\section{Discussion}

To the best of our knowledge, the present research is the first comprehensive study about nutrition labels on pre-packaged foods in Serbia. The strength of the study is that the analysis was carried out in retail stores, replicating the conditions in which consumers shop daily. It provides an insight into the real-life exposure of consumers to nutrition labels.

The results show that two-thirds of the examined products contained nutrition information; $62.7 \%$ of the products displayed nutrition information on the back of the packaging (BOP) and $19.1 \%$ on the front of the packaging (FOP). According to the Codex Alimentarius standards all foods should have a nutrition declaration ${ }^{(34)}$, which can be considered the 'gold standard'. If we compare the current situation in Serbia with this benchmark, the results presented herein may be considered unsatisfactory. One of the possible explanations may be related to the fact that in Serbia, at the time of the survey, nutrition labelling on pre-packaged foods was voluntary unless food products contained nutrition and/or health claims $^{(25)}$. At present, there are no regulations at the state level which encourage food manufacturers to provide a nutrition declaration and improve their products in order to achieve higher nutritional quality. Serbia is still far away from countries such as the USA, Australia and New Zealand, where the prevalence of nutrition information has already reached $100 \%{ }^{(35,36)}$.

The EU funded a project called 'Food Labelling to Advance Better Education for Life (FLABEL)' aiming to assess the penetration of nutrition labelling on various food products in all twenty-seven EU Member States and Turkey. The survey revealed different results across several European countries ${ }^{(14)}$. That study identified the UK and Ireland as the leading countries in food nutrition labelling. These countries, however, may not be comparable with Serbia, considering their level of development. It would be more appropriate to compare Serbia with Slovenia and Turkey. Slovenia, a current member of the EU, was a former Yugoslav republic as was Serbia. Turkey is the only country in the project that is not an EU member, but is on the path towards EU, similarly to Serbia. In these two countries the penetration of nutrition food labelling was at the lowest level. The average European penetration of BOP was $85 \%$, but in Slovenia was $70 \%$. The UK showed the highest penetration of FOP (82\%), while Turkey had the lowest (24\%). In comparison with that, the results obtained in Serbia are unsatisfactory especially considering that the survey was conducted three years later. In particular, a major drawback is the rare presence of FOP signposting in Serbia. Some researchers suggest that placing nutrition information on the front of packaging is more effective than on the side or on the $\operatorname{back}^{(37,38)}$.

Apart from the fact that the nutrition information was not regularly present, our research study found some other problems as well. The nutrition tables are not uniform, both in their contents and in their form. The wide range of different contents of nutrition information noticed among packaged foods in Serbia can be explained by the domestic regulations. These give manufacturers the freedom to present nutrition information in the way that suits them best. For example, manufacturers can choose to present nutrition information as the 'Big 4', the 'Big 8' or in other forms. Our suggestion is that the contents of the nutrition declaration should always be in the form of the 'Big 8'. We therefore consider the current situation unsatisfactory because of the frequent presence of insufficient information. In our study, the 'Big 4' was observed twice as often as the 'Big 8'. This finding is in contrast with the FLABEL results, which generally reported that the 
'Big 8' was more frequent than the 'Big 4' (49\%v. 34\%) ${ }^{(14)}$. There were some countries, however, where the situation was similar to that in Serbia: Turkey, Lithuania, Latvia, Estonia and Bulgaria; these countries have a poor trend of nutrition labelling.

The form of the information, such as the letter size, is of crucial importance for consumers. The consumer should be able to read the nutrition information and make the adequate choice accordingly. At the time of the present study, Serbia did not have any legislation regulating the legibility of nutrition information. This implies that the legibility of the food nutrition labelling was left to the food manufacturers. It is therefore not surprising that we found poor legibility of nutrition declarations in almost one-third of all surveyed products. Defining the minimum font size is crucial in improving the nutrition declaration. The current EU standards state that the $x$-height of the font size should be equal to or greater than $1.2 \mathrm{~mm}^{(26)}$. Nutrition declarations, even when being the right size and form, do not always provide consumers with all of the necessary information they require in a user-friendly format ${ }^{(39)}$.

Given the current situation in Serbia, the purpose of the nutrition declaration is compromised. The real question is whether manufacturers have a truthful intention to inform consumers about the product or are just using these ineligible labels as a marketing tool. Faced with a variety of unreadable messages, the consumer can feel confused and may easily give up on reading the declaration and choose other, more aggressively advertised products. Similar problems were observed by researchers in China who proposed necessary improvements and legislation in this $\operatorname{area}^{(40)}$

Recently the focus of interest is on the type of food labels, which should not only provide information but also give advice to consumers. The evidence reveals that most consumers have problems interpreting this information when selecting a healthy diet ${ }^{(39)}$. According to the recommendations by Rayner et al., all foods should have simply designed supplementary nutrition information which at least can be interpreted, such as the traffic light labelling. The number of these schemes in use should be one ${ }^{(22)}$. In Serbia, the FOP scheme was present on $19 \cdot 1 \%$ of all surveyed products, and the GDA value within the FOP scheme on $12.6 \%$ of all products. The proportion of GDA information is similar to the situation in Slovenia, but higher than in Turkey, where the GDA is located on only $2 \%$ of products. This is far less than in the UK and Ireland (63\% and $58 \%$, respectively) where this type of food labelling is being actively promoted ${ }^{(14)}$. The traffic light warning system, which greatly enhances the ability of consumers to assess the nutritional value and quality of food ${ }^{(24)}$, was not observed in Serbia. We conclude that the observed situation in our study differs from the proposed benchmark.

The presence of a health logo, which by definition is approved by the legal authorities, is widely compromised in Serbia. In fact, in Serbia there are no legal health authorities that either assign these symbols or clearly define nutrition criteria that need to be fulfilled by a particular food product. The existence of different arbitrary symbols on the packaging is very challenging because it can mislead the consumer. This area requires serious regulations, which are already present in the other developed countries, especially Sweden and The Netherlands ${ }^{(41,42)}$.

Some products on the Serbian market display health claims which suggest that certain foods heal and/or prevent certain diseases. We find such claims unacceptable. All health claims should be based on medical evidence and should meet particular Codex Alimentarius standards ${ }^{(33)}$. At present, no such standards exist in Serbia. This allows food manufacturers to manipulate and deceive consumers using these misleading clams as marketing tools for the deception.

Unlike health claims, the use of nutritional claims is regulated by law in Serbia ${ }^{(27)}$. Nutrition claims were encountered on $6.3 \%$ of the products in the present survey, which is less than in other developed countries. In the EU, on average, $25 \%$ of the products had nutrition claims $^{(14)}$, while in Ireland nutrition claims were recorded on nearly half of the products $(47 \cdot 3 \%)^{(43)}$. The importance of clear and truthful nutrition and health claims was noted by Barreiro-Hurlé et $a l .{ }^{(44)}$. They indicate that such claims may reach out to those who are less likely to read nutrition labels, such as people with lower nutrition knowledge or more hedonic lifestyles ${ }^{(44)}$.

The results of our study indicate a need to improve the nutrition declaration in Serbia. This would greatly assist consumers in selecting products according to their health condition and the available guidelines. It is believed that such labelling would encourage food manufacturers to improve the quality of their products. This was observed in The Netherlands once a simple 'healthy choice' FOP logo was introduced ${ }^{(45)}$.

In the authors' experience, food manufacturers are generally reluctant to accept any suggestion of a food labelling system unless it is legally enforced. Legislation is more efficient than the various recommendations and incentives up to a certain extent ${ }^{(35,40)}$.

The present study faced several limitations. Gathering of the data and the survey took place in Belgrade, the capital of Serbia, the largest and most developed city in country, in the largest stores. Smaller shops and stores in rural regions were not taken into consideration. We may therefore have omitted to analyse products by less known local producers and/or illegally imported products from neighbouring countries. The impact of this omission is likely to be negligible because of the fewer number of such products. Hence, it should not have any significant impact on the obtained results. We failed to survey all of the available product categories on the market. Instead, we chose ten listed categories of products that consumers commonly use in their everyday diet and that are officially included in the consumption basket. 


\section{Conclusion}

To the authors' knowledge, the present research study is the first one on nutrition labelling carried out in Belgrade, Serbia. It reveals that the current situation of nutrition labelling is poor and rather unsatisfactory. The greater involvement of relevant legal health authorities and the improvement of legislation will improve the current situation, particularly given the forthcoming harmonization with the EU regulations. These results provide the basis for subsequent studies involving the reading, the understanding and the use of the nutrition labels by consumers in Serbia.

\section{Acknowledgements}

Financial support: This work was supported by the Ministry of Education and Science, Serbia (contract number OI 175067). The funder had no role in the design, analysis or writing of this article. Conflict of interest: None. Authorship: D.B.D. and J.B.J. conceived and designed the study. D.B.D., D.V.T. and K.Ž.P. collected the data. D.B.D. and J.B.J. wrote the paper. N.D.V. and J.B.J. made critical corrections and revised the manuscript. Ethics of buman subject participation: Not applicable.

\section{References}

1. World Health Organization (2013) Global Health Observatory (GHO): Obesity Situation and trends 2008. http://www. who.int/gho/ncd/risk_factors/obesity_text/en/index.html (accessed March 2014).

2. Flegal KM, Graubard BI, Williamson DF et al. (2007) Causespecific excess deaths associated with underweight, overweight, and obesity. JAMA 298, 2028-2037.

3. Field AE, Coakley EH, Must A et al. (2001) Impact of overweight on the risk of developing common chronic diseases during a 10-year period. Arch Intern Med 161, 1581-1586.

4. DeVallance E, Fournier SB, Donley DA et al. (2014) Is obesity predictive of cardiovascular dysfunction independent of cardiovascular risk factors? Int J Obes (Lond) (Epublication ahead of print version).

5. Bayram F, Kocer D, Gundogan K et al. (2014) Prevalence of dyslipidemia and associated risk factors in Turkish adults. J Clin Lipidol 8, 206-216.

6. Brown CD, Higgins M, Donato KA et al. (2000) Body mass index and the prevalence of hypertension and dyslipidemia. Obes Res 8, 605-619.

7. World Health Organization (2003) Diet, Nutrition and the Prevention of Chronic Diseases. Joint WHO/FAO Expert Consultation. WHO Technical Report Series no. 916. Geneva: WHO.

8. Wiseman M (2008) The second World Cancer Research Fund/American Institute for Cancer Research expert report. Food, nutrition, physical activity, and the prevention of cancer: a global perspective. Proc Nutr Soc 67, 253-256.

9. European Commission (2010) Strategy for Europe on Nutrition, Overweight and Obesity Related Health Issues Implementation Progress Report. Brussels: EC.

10. Ministry of Health of the Republic of Serbia (2007) Health Survey of the Population of Serbia 2006: Final Report (in Serbian). http://download.moh1.googlepages.com/ FinalniIzvestaj-IstrazivanjeZdravlja.pdf (accessed March 2014).

11. Sicree R, Shaw JE \& Zimmet PZ (2009) The global burden of diabetes. In Diabetes Atlas, 4th ed., pp. 21-37 [D Gan, editor]. Brussels: International Diabetes Federation.

12. Rona RJ, Keil T, Summers C et al. (2007) The prevalence of food allergy: a meta-analysis. J Allergy Clin Immunol 120, 638-646.

13. Sicherer SH \& Sampson HA (2006) Food allergy. J Allergy Clin Immunol 117, 2 Suppl., S470-S475.

14. Storcksdieck genannt Bonsmann S, Celemín LF, Larrañaga A et al. (2010) Penetration of nutrition information on food labels across the EU-27 plus Turkey. Eur J Clin Nutr 64, $1379-1385$.

15. World Health Organization (2004) Global Strategy on Diet, Physical Activity and Health. Geneva: WHO.

16. Mhurchu CN \& Gorton D (2007) Nutrition labels and claims in New Zealand and Australia: a review of use and understanding. Aust N Z J Public Health 31, 105-112.

17. Campos S, Doxey J \& Hammond D (2011) Nutrition labels on pre-packaged foods: a systematic review. Public Health Nutr 14, 1496-1506.

18. Neuhouser ML, Kristal AR \& Patterson RE (1999) Use of food nutrition labels is associated with lower fat intake. J Am Diet Assoc 99, 45-53.

19. Kim SY, Nayga RM Jr \& Capps O (2001) Food label use, selfselectivity, and diet quality. J Consum Aff 35, 346-363.

20. Fitzgerald N, Damio G, Segura-Pérez S et al. (2008) Nutrition knowledge, food label use, and food intake patterns among Latinas with and without type 2 diabetes. J Am Diet Assoc 108, 960-967.

21. Kristal AR, Hedderson MM, Patterson RE et al. (2001) Predictors of self-initiated, healthful dietary change. $\mathrm{J} \mathrm{Am}$ Diet Assoc 101, 762-766.

22. Rayner M, Wood A, Mhurchu et al. (2013) Monitoring the health-related labelling of foods and non-alcoholic beverages in retail settings. Obes Rev 14, Suppl. 1, 70-81.

23. Hersey JC, Wohlgenant KC, Arsenault JE et al. (2013) Effects of front-of-package and shelf nutrition labeling systems on consumers. Nutr Rev 71, 1-14.

24. Hawley KL, Roberto CA, Bragg MA et al. (2013) The science on front-of-package food labels. Public Health Nutr 16, 430-439.

25. Ministry of Agriculture, Forestry and Water Management of the Republic of Serbia (2013) Regulation on nutrition labelling and advertising for foodstuffs. Sl. glasnik RS 85/13 (in Serbian).

26. European Commission (2011) Regulation (EU) No 1169/ 2011 of the European Parliament and of the Council of 25 October 2011 on the provision of food information to consumers. Official Journal of the European Union L304, $18-63$.

27. Ministry of Internal Economic Relations (2004) Regulation on nutrition labelling for foodstuffs. Sl. list SCG 4/2004, 12/ 2004, 48/2004 (in Serbian).

28. European Commission (2006) Regulation (EC) No 1924/ 2006 of the European Parliament and of the Council of 20 December 2006 on nutrition and health claims made on foods. Official Journal of the European Union L404, 9-25.

29. Statistical Office of the Republic of Serbia (2010) Methodological notes on calculating a consumption basket (in Serbian). http://mtt.gov.rs/wp-content/uploads/2010/09/ IzvodIzMetodPotrosackeKorpe_2010.pdf (accessed September 2014).

30. European Commission (1990) Council Directive 90/496/EEC of 24 September 1990 on nutrition labelling for foodstuffs. Official Journal of the European Communities L276, 40-44. 
31. European Commission (2008) Regulation of the European Parliament and of the Council of 30 January 2008 on the provision of food information to consumers. Final Report. http://ec.europa.eu/food/food/labellingnutrition/ foodlabelling/publications/proposal_regulation_ep_council. pdf (accessed March 2014).

32. IGD Working Group Report (2005) Report of the IGD/PIC Industry Nutrition Strategy Group Technical Working Group on Guideline Daily Amounts (GDAs). Watford: Institute of Grocery Distribution.

33. Codex Alimentarius Commission (various years) Guidelines for Use of Nutrition and Health Claims, CAC/GL 23-1997. Revised in 2004. Amended in 2001, 2008, 2009, 2010, 2011 and 2012. Annex adopted in 2009. Rome: FAO/WHO.

34. Codex Alimentarius Commission (various years) Guidelines on Nutrition Labelling, CAC/GL 2-1985. Revisions 1993 and 2011. Amended in 2003, 2006, 2009, 2010, 2012 and 2013. Annex adopted in 2011 and revised in 2013. Rome: FAO/ WHO.

35. Legault L, Brandt MB, McCabe N et al. (2004) 2000-2001 food label and package survey: an update on prevalence of nutrition labeling and claims on processed, packaged foods. J Am Diet Assoc 104, 952-958.

36. AgriQuality Australia Pty Ltd \& Food Standards Australia New Zealand (2006) On-going Food Label Monitoring Survey in Australia and New Zealand - Report on the Assessment of 2005 Labels for Nutrition, Health and Related
Claims. Canberra: AgriQuality Australia Pty Ltd and Food Standards Australia New Zealand.

37. Grunert K (2007) A review of European research on consumer response to nutrition information on food labels. J Public Health 15, 385-389.

38. Wansink B (2003) How do front and back package labels influence beliefs about health claims? J Consum Aff 37, 305-316.

39. Temple NJ \& Fraser J (2014) Food labels: a critical assessment. Nutrition 30, 257-260.

40. Wang S, Chen Y, Liu M et al. (2011) The changes of nutrition labeling of packaged food in Hangzhou in China during 2008-2010. PLOS ONE 6, e28443.

41. Swedish National Food Administration (2007) The Keyhole symbol. http://www.slv.se/en-gb/Group1/Food-and-Nutrition/ Keyhole-symbol/ (accessed March 2014).

42. Choices International Foundation (2007) Homepage. http:// www.choicesprogramme.org/en (accessed March 2014).

43. Lalor F, Kennedy J, Flynn MA et al. (2010) A study of nutrition and health claims - a snapshot of what's on the Irish market. Public Health Nutr 13, 704-711.

44. Barreiro-Hurlé J, Gracia A \& de-Magistris T (2010) Does nutrition information on food products lead to healthier food choices? Food Policy 35, 221-229.

45. Vyth EL, Steenhuis IH, Roodenburg AJ et al. (2010) Front-ofpack nutrition label stimulates healthier product development: a quantitative analysis. Int J Behav Nutr Phys Act 7, 65. 